\title{
Body fat percentage, BMI and skinfold thickness among medical students in Sabah, Malaysia
}

\author{
Thant Zin ${ }^{1}$, Aza Sherin Mohamad Yusuff ${ }^{2}$, Than Myint ${ }^{3}$, Daw K. S. Naing ${ }^{4}$, Kyaw Htay ${ }^{5}$, Aye Aye Wynn ${ }^{6}$ \\ ${ }^{1}$ Foremer Senior Lecturer, ${ }^{2}$ Senior Lecturer, ${ }^{3}$ Associate Professor and Head, Rural Medicine Research Unit; ${ }^{4}$ Associate Professor, \\ Community and Family Medicine Department; ${ }^{5}$ Associate Professor, Surgical Base Department; ${ }^{6}$ Senior Lecturer, Pathobiology \\ and Diagnostic Department; School of Medicine, University Malaysia Sabah, Kota Kinabalu, Sabah, Malaysia.
}

\begin{abstract}
Nutrition is a critical part of human health and development. However, overweight and obesity prevalence are rising worldwide, with associated diabetes, cardiovascular diseases and other diet-related conditions. Body mass index (BMI) is an index of weight-for-height that is commonly used to classify overweight and obesity in adults. The skinfold measurement method is the most widely used body fat composition testing method for assessing body fat percentage. The objective of the study was to measure the body weight and body fat of medical students of Sabah, Malaysia by using different types of nutritional assessment methods. A cross-sectional study among the selected Year 2 medical students of School of Medicine, University Malaysia Sabah was conducted using different types of nutritional assessment. The average BMI and mean body fat percentage measured by body fat analyzer of the respondents were $21.95 \pm 0.59 \mathrm{~kg} / \mathrm{m}^{2}$, and $16.98 \pm 1.37 \%$ respectively. The mean body fat percentages calculated by different skinfold thickness were: abdominal $24.13 \pm 1.11 \%$, supra-iliac $20.35 \pm 1.35 \%$, subscapular $21.83 \pm 1.01 \%$, and alternative three-site $19.46 \pm 1.02 \%$. In reliability testing, results are variable between male and female - internal consistency of the alternative three-sites skinfold calculation for body fat percentage showed male (excellent) and female (acceptable), and skinfold reading for body fat percentage for triceps, abdomen, sub-scapular and supra-iliac showed male (good) and female (poor to acceptable). Our findings could be used in obesity awareness promotion among Malaysian youth. However, further investigation about the determinants of obesity and body fat, including age, sex, race, nutrition, and changes over time, is needed.
\end{abstract}

Keywords: Body fat percentage, BMI, Skinfolds thickness, Obesity, Medical students.

\section{Introduction}

Nutrition is important in human health and development. ${ }^{1}$ It is a major contributor to health, disease and early death. ${ }^{1,2}$ Nutrition is usually related to chronic health problems so that nutritional problems in childhood may continue into adult life. ${ }^{2}$ Furthermore, better nutrition is vital for child and maternal health, stronger immune systems, reduced risk of non-communicable diseases i.e. diabetes and cardiovascular and increase longevity. ${ }^{2,3}$ Moreover, people with adequate nutrition are not only more productive but also more efficient in breaking the cycles of poverty and hunger. ${ }^{3}$

Nowadays, a double burden of malnutrition is affecting the whole world that includes both under nutrition and overweight. ${ }^{3}$ There is much evidence for over nutrition worldwide, seen in rising overweight and obesity, diabetes, cardiovascular diseases and other diet-related problems. ${ }^{4}$ Overweight and obesity are the abnormal and excessive fat accumulation in the body. Obesity is preventable; however, according to the World Health Organization (WHO), overweight and obesity are the fifth leading risk for global deaths in 2013; 2.8 million adults die as a result of being overweight or obese. ${ }^{4}$ In addition, $44 \%$ of the diabetes burden, $23 \%$ of the ischemic heart disease burden and $7-41 \%$ of certain cancer burdens are attributable to overweight and obesity. ${ }^{4}$

\section{Practice Points}

- BMI is an index of weight-for-height that is commonly used to classify overweight and obesity in adults. The skinfold measurement method is the most widely used body fat composition testing method for assessing body fat percentage.

- The average BMI and body fat of the respondents was $21.95 \pm 0.59 \mathrm{~kg} / \mathrm{m}^{2}$, and $16.98 \pm 1.37 \%$ respectively.

- The body fat percentages in relation to skinfold thickness were: abdominal $24.13 \pm 1.11 \%$, suprailiac $20.35 \pm 1.35 \%$, subscapular $21.83 \pm 1.01 \%$, and alternative three-site $19.46 \pm 1.02 \%$.

- Body fat percentage measurements had an excellent to good internal consistency and greater reliability for male students when compare with female counterparts.

- Further research about the determinants of obesity and body fat, including age, sex, race, nutrition, and changes over time, is needed.

Correspondence: Dr Thant Zin, Foremer Senior Lecturer, School of Medicine, University Malaysia Sabah, Kotakinabalu, Sabah, Malaysia, 88450. Email thantzinphdc@gmail.com. 
Body mass index (BMI) is an index of weight-for-height for categorizing overweight and obesity in adults. ${ }^{4-6}$ It is calculated as a person's weight in kilograms divided by the square of his height in meters $\left(\mathrm{kg} / \mathrm{m}^{2}\right)$. WHO classify overweight and obesity as a BMI greater than or equal to 25 and 30 respectively; however, BMI may not correspond to the same degree of fatness in different individuals. ${ }^{4,6,7}$

The measurement of the human body, in terms of the dimensions of bone, muscle, and adipose (fat) tissue, is the study of anthropometry. ${ }^{5}$ The United States National Health and Nutrition Examination Survey [(Center for Disease Control and Prevention (CDC) $]^{5}$ used anthropometric measurement data to evaluate: body composition changes that occur over the adult lifespan, health and dietary status, and disease risk. Generally, CDC used the following anthropometry measures for nutritional assessment: weight, head circumference, recumbent length, standing height, upper leg length, upper arm length, arm circumference, abdominal (waist) circumference, and skinfolds. ${ }^{5}$

Skinfold measurement is a widely used body composition testing method for assessing body fat percentage (BFP). ${ }^{5}$ A skinfold caliper is used for measuring thickness of skin and transformed or computed into body fat composition in percentage. Different type of skinfold caliper measures a double layer of skinfold thickness in mm, mostly from three to nine different anatomical sites around the body. ${ }^{5,6}$

The health risks associated with obesity are not always constant. Some literature argues about the relationship between health risks and a lower BMI in Asian populations, as evidenced by a high prevalence of type 2 diabetes mellitus and cardiovascular risk factors that occur at a BMI below $25 \mathrm{~kg} / \mathrm{m}^{2} .{ }^{8}$ Furthermore, there is also evidence of a higher percentage of body fat among Asian subjects at a similar BMI cut-off point compared to Caucasian subjects, indicating the risk of obesityrelated diseases among Asians increases from a lower BMI of $23 \mathrm{~kg} / \mathrm{m}^{2} .8-10$ Obesity statistics in Malaysia as reported by the National Health and Morbidity Survey 1996 were: adult males $15.1 \%$ were overweight and $2.9 \%$ obese and adult females $17.9 \%$ were overweight and $5.7 \%$ obese. $^{11}$ Furthermore, there was little difference between rural and urban populations and racial variation; Malays were more obese than Indians and Indians were more obese than Chinese. ${ }^{11}$ Healthcare costs for obesity can be both direct - preventive, diagnostic and treatment services - and indirect - costs refer to the value of salary lost by people unable to work because of illness or disability, as well as the value of future earnings lost by premature death and ultimately the quality of life lost to society. ${ }^{12}$

The objective of the present study was to explore body weight and body fat in Year 2 medical students of Sabah, Malaysia by using different types of nutritional assessment methods. The study would also report on the prevalence of obesity, average BMI and body fat composition among the medical students, and examine the reliability and accuracy of different types of anthropometric measurement tools.

\section{Materials and Methods}

This cross-sectional study was conducted among Year 2 medical students of School of Medicine, University Malaysia Sabah to analyze anthropometric parameters in relation to height, weight, skinfold and BMI, and predicting body fat percentage. All students of year 2 were included when they were attending a nutritional practical class on the day of survey.

Students were thoroughly explained and demonstrated the different types of nutritional measurements. Students conducted the examination in pair and they measured each other's anthropometric parameters. For consistency, only the right side of the body was used to measure the skinfold thickness. The student pinched the skin at the appropriate site and raises the double layer of skin and the underlying adipose tissue, but not the muscle. Skinfold measurements immediately after physical activity were not allowed because there might be a possible fluid shift to the skin and incorrect estimates. ${ }^{13}$ As per CDC guidelines for measurement, the calipers were applied $(1 \mathrm{~cm})$ below and at right angles to the pinch, and a reading in millimeters $(\mathrm{mm})$ taken two seconds later. ${ }^{5}$ To prevent measurement error, we measured twice and the mean of two measurements was taken or a third measurement was done (if two measurements differed greatly), then the median value taken.

Three standard measurement tools were used: TANITA Body Composition Analyzer (SC 330 model, Max $270 \mathrm{~kg}$, Min $2 \mathrm{~kg}, \mathrm{e}=0.1 \mathrm{~kg}, \mathrm{~T}=10 \mathrm{~kg}$, Body Fat \%; Range 3-75\%, Increment $0.1 \%$ ), SECA Height and Weight Scale, and Accu-Measure for Skinfold measurement available at the School of Medicine, Universiti Malaysia Sabah. ${ }^{5,7,14-16}$ Proper instruction and a demonstration had been given before the assessment. Four site skinfold thickness, namely triceps, abdomen, supra-iliac and sub-scapular was measured and body fat composition calculated by Accu-Measure and Lab A6-3 alternative skinfold measurement formula using three sites skinfold (Abdomen, Supra-iliac, Triceps) ${ }^{17}$; Male $\{(0.39287 \times$ sum of three skinfolds $)-(0.00105 \times$ [sum of three skinfolds $\left.]^{2}\right)+(0.15772 \times$ age $\left.)-5.18845\right\}$ and Female $\{(0.41563 \times$ sum of three skinfolds $)-(0.00112$ $\left.\times[\text { sum of three skinfolds }]^{2}\right)+(0.03661 \times$ age $)+$ $4.03653\}$.

Data analyses have been done using statistical package SPSS 21 available in the Universiti Malaysia Sabah. Descriptive statistics for baseline indicators and skinfold thickness and body fat composition were shown for all students. Regression analysis for BMI, weight, height and skinfold body fat was done. Obesity was calculated according to the Malaysia Obesity Classification: under nutrition $\left(<18.5 \mathrm{~kg} / \mathrm{m}^{2}\right)$, normal $\left(18.5-22.9 \mathrm{~kg} / \mathrm{m}^{2}\right)$, over weight $\left(\geq 23 \mathrm{~kg} / \mathrm{m}^{2}\right)$, and obese $\left(\geq 27.5 \mathrm{~kg} / \mathrm{m}^{2}\right){ }^{10}$ Reliability tests for body fat composition measurements: skinfolds - triceps, abdomen, supra-iliac, sub-scapular and three sites - and body analyzer have been done. 
The ethical permission of the study was granted by the Ethical Committee, School of Medicine, University Malaysia Sabah, Sabah State, Malaysia.

\section{Results}

Anthropometric data was collected from 40 students. The mean age of the students was 20.18 years. In analysis, mean of baseline anthropometric measurements were: weight $59.39 \pm 2.10 \mathrm{~kg}$, height $1.63 \pm 0.01 \mathrm{~m}$, BMI $21.95 \pm 0.59 \mathrm{~kg} / \mathrm{m}^{2}$; and skinfold thickness in four sites were: triceps $20.37 \pm 1.14 \mathrm{~mm}$, abdominal $23.04 \pm 1.23 \mathrm{~mm}$, supra-iliac $17.44 \pm 1.24 \mathrm{~mm}$ and sub-scapular $19.22 \pm 1.11 \mathrm{~mm}$. Furthermore, the mean body fat percentages calculated by different skinfold thickness were: abdominal $24.13 \pm 1.11 \%$, suprailiac $20.35 \pm 1.35 \%$, subscapular $21.83 \pm 1.01 \%$, and alternative three-site $19.46 \pm 1.02 \%$ (Table 1 ).

According to the Malaysia Obesity Classification, ${ }^{10}$ students' BMI was classified into underweight (male $10 \%$, female $21 \%$ ), normal weight (male $57 \%$, female
$63 \%$ ), pre-obese/overweight (male $24 \%$, female $11 \%$ ), and obese (male $10 \%$, female $5 \%$ ) (Table 2 ).

In reliability testing, body fat percentages in different methods were compared with standard body fat analyzer (TANITA) readings and following readings were found (Table 3):

- Three-site skinfold thickness calculation reliability test (Cronbach's alpha); male 0.906 (excellent internal consistency) and female 0.67 (acceptable internal consistency)

- Reading for skinfold thickness in millimeters (Body Fat Interpretation Chart) reliability test (Cronbach's alpha); 1) Triceps - male 0.888 and female $0.504,2$ ) Abdomen - male 0.887 and Female 0.565 , 3) Supra-iliac - male 0.855 and female 0.609 , and 4) sub-scapular - male 0.861 and female 0.634 .

Table 1: Descriptive statistics: skinfold measurement and selected baseline indicators $(\mathrm{n}=40)$

\begin{tabular}{|c|c|c|c|c|}
\hline Variables & Mean & Std. Error & Minimum & Maximum \\
\hline Age & 20.18 & 0.07 & 19.00 & 21.00 \\
\hline Weight (kg) & 59.39 & 2.10 & 41.00 & 94.30 \\
\hline Height $(\mathrm{m})$ & 1.63 & 0.01 & 1.50 & 1.80 \\
\hline Body Mass Index (BMI kg/m²) & 21.95 & 0.59 & 16.90 & 35.50 \\
\hline $\begin{array}{l}\text { Mean Body Fat \% measured by Body } \\
\text { Composition Analyzer }\end{array}$ & 16.98 & 1.37 & 3.10 & 42.10 \\
\hline Triceps Skinfold Thickness (mm) & 20.37 & 1.14 & 5.00 & 41.00 \\
\hline Abdominal Skinfold Thickness (mm) & 23.04 & 1.23 & 6.40 & 40.00 \\
\hline Supra-iliac Skinfold Thickness (mm) & 17.44 & 1.24 & 4.40 & 36.00 \\
\hline Sub-scapular Skinfold Thickness (mm) & 19.22 & 1.11 & 9.00 & 41.00 \\
\hline Body Fat $\%$ by Triceps Skinfold & 22.60 & 1.29 & 3.90 & 35.20 \\
\hline Body Fat $\%$ by Abdominal Skinfold & 24.13 & 1.11 & 6.20 & 35.20 \\
\hline Body Fat \% by Supra-iliac Skinfold & 20.35 & 1.35 & 3.90 & 35.20 \\
\hline Body Fat $\%$ by Sub-scapular Skinfold & 21.83 & 1.01 & 9.50 & 35.20 \\
\hline Body Fat $\%$ by Three site Calculation & 19.46 & 1.02 & 3.91 & 33.43 \\
\hline
\end{tabular}

Table 2: BMI classification of Year 2 medical students

\begin{tabular}{|c|l|c|c|}
\hline Gender & \multicolumn{1}{|c|}{ Obesity Classification } & Frequency (\%) & BMI Range \\
\hline \multirow{4}{*}{ Male } & Underweight (BMI<18.5) & $2(10 \%)$ & $16.95-17.75$ \\
\cline { 2 - 4 } & Normal Weight (BMI 18.5 - 22.9) & $12(57 \%)$ & $18.89-22.88$ \\
\cline { 2 - 4 } & Pre-Obese (BMI 23.0 - 27.4) & $5(24 \%)$ & $24.47-26.86$ \\
\cline { 2 - 4 } & Obese (BMI $\geq 27.5)$ & $2(10 \%)$ & $27.78-30.12$ \\
\hline \multirow{4}{*}{ Female } & Underweight (BMI $<18.5)$ & $4(21 \%)$ & $19.01-18.31$ \\
\cline { 2 - 4 } & Normal Weight (BMI 18.5 - 22.9) & $12(63 \%)$ & $23.15-24.62$ \\
\cline { 2 - 4 } & Pre-Obese (BMI 23.0 - 27.4) & $2(11 \%)$ & 35.49 \\
\cline { 2 - 4 } & Obese (BMI $\geq 27.5)$ & $1(5 \%)$ & $16.95-35.49$ \\
\hline \multicolumn{2}{|l}{ Total: Male and Female } & 40 & \\
\hline
\end{tabular}

Table 3: Reliability test for different methods of body fat percentage

\begin{tabular}{|l|c|c|}
\hline \multicolumn{1}{c|}{ Reliability Models } & \multicolumn{2}{c|}{ Cronbach's alpha } \\
\cline { 2 - 3 } & Male & Female \\
\hline BFP Alternative three site Calculation and Body Fat Analyzer & 0.906 & 0.670 \\
\hline BFP by Skinfold Thickness (Triceps) and Body Fat Analyzer & 0.888 & 0.504 \\
\hline BFP by Skinfold Thickness ( Abdominal ) and Body Fat Analyzer & 0.887 & 0.565 \\
\hline BFP by Skinfold Thickness ( Supra-iliac ) and Body Fat Analyzer & 0.855 & 0.609 \\
\hline BFP by Skinfold Thickness ( Sub-scapular ) and Body Fat Analyzer & 0.861 & 0.634 \\
\hline
\end{tabular}




\section{Discussion}

Based upon the Malaysia Obesity Classification, the study showed a higher prevalence of overweight (24\%) and obese $(10 \%)$ among male students and a lower prevalence of overweight (11\%), and obese (5\%) among female students. Male students were found to be obese than the national level when compared with findings of the Malaysia National Health and Morbidity Survey $1996,{ }^{11}$ which reported that $2.9 \%$ obese among adult males, and 5.7\% obese among adult females. ${ }^{11}$ As reported by many studies, BMI is commonly used to determine overweight and obesity in clinical and field research settings. ${ }^{18,19}$ However, there is some debate about the relationship between BMI and body fat; three studies have highlighted that BMI does not distinguish between lean and fat body mass. ${ }^{19-20}$ Moreover, Peltz et al. reported that BMI is neither reliable nor sufficient for identifying individuals with obesity and the incidence of obesity based solely on BMI has the potential to be substantively biased. ${ }^{21}$

On the other hand, some studies reported that distribution of body fat acts as a predictor of metabolic disturbances, cardiovascular disease, cancers, and premature mortality. ${ }^{19,22-23}$ There are various methods which can estimate body adiposity. The most commonly used method, the skinfold thickness measurement - which assesses body fatness through the use of calipers at particular body sites - has shown a strong correlation with reference methods. ${ }^{24,25}$ Another assessment method, the body composition analyzer which measures body fatness through bioelectrical impedance analysis (BIA) - is widely used in clinical and research settings. ${ }^{26,27}$ BIA has been widely used as a validated measurement of body adiposity when compared to reference methods such as underwater weighing (UWW) and dual energy X-ray absorptiometry (DEXA). ${ }^{26-28}$ In our study, body fat percentage (BFP) measured by different methods were: body composition analyzer (16.98 $\pm 1.37 \%)$, triceps skinfold $(22.6 \pm 1.29 \%)$, abdominal skinfold $(24.13 \pm 1.11 \%)$, supra-iliac skinfold $(20.35 \pm 1.35 \%)$, sub -scapular skinfold $(21.83 \pm 1.01 \%)$ and the alternative three-site calculation formula $(19.46 \pm 1.02 \%)$, but there was no consistency between the methods. Some studies suggested that, age, gender, ethnicity, and physical activity level are also recommended to be considered for greater precision in the BIA and skinfold equation. ${ }^{29,30}$

Measurement reliability is the most essential factor in every research. It is directly related to data quality. Generally, probability of any relationships among variables of the study could be increased by reducing errors in the measurement. Lohman and colleagues' standardization of measurement techniques in anthropometry, developed by late 1980s, could be used as a guide and reference for reliable anthropometric measurements. ${ }^{31,32}$ However, there is still a problem in the uniformity of method when collecting reliable data and reporting the statistics of a reliability assessment. $^{31,33-35}$
This study also calculated reliability test for different measurements of body fat percentage (BFP). Cronbach's alpha is commonly accepted for describing measurement of internal consistency by George and Maller Simple Guide; $\geq 0.90$ (excellent), $0.7 \leq-<0.9$ (good), $0.6 \leq-<0.7$ (acceptable), $0.5 \leq-<0.6$ (poor) and $<0.5$ (unacceptable). ${ }^{36,37}$ The reliability test for the alternative three-sites skinfold calculation for body fat percentage $(\mathrm{BFP})^{17}$ showed excellent and acceptable internal consistency - Cronbach's alpha; male 0.906 and female 0.67. The test of BFP from reading the skinfold thickness for triceps, abdomen, sub-scapular and suprailiac showed good to poor internal consistency where male were good and female were poor to acceptable Cronbach's alpha for four sites; male $(0.888,0.887$, $0.855,0.861)$ and female $(0.504,565,609,634)$. The body fat percentage of females, our BFP findings had a lower reliability power compared to the males. There is a similar report about the difference between the sexes regarding fat deposit - women have greater abdominal subcutaneous fat and far less intra-abdominal fat than men - and body fat mass - different formula for male and females' BMI/body fat and skinfold thickness relationship. ${ }^{30}$

There are some limitations in this study. This is a crosssectional observation and provides an association between variables. Unlike a longitudinal observation, a cross-sectional study could not verify changes in the effects of the variables. Next, the measurements were taken by the students themselves who followed the instructions provided by the researcher. Finally, in this purposive and one-point cross-sectional study neither other important variables (e.g. BMI, such as race, height, age, and sex) nor changes throughout life were able to be analyzed.

\section{Conclusion}

Our study showed a higher level of overweight and obesity among male medical students than the Malaysian national standard. This is important because overweight and obesity are preventable but are the fifth leading cause of global deaths in 2013. Moreover, they are risk factors for diabetes, heart diseases and cancers. Furthermore, body fat percentage measurements had an excellent to good internal consistency and greater reliability for male students - skinfold thickness reading and alternative three-sites skinfold calculation - and a relatively acceptable to poor internal consistency and lower reliability for female students, but lower than the male students' results - skinfold thickness reading and alternative three-sites skinfold calculation. Finally, the relatively lower internal consistency and reliability for the measurement of skinfold thickness and body fat composition among female students will need more facts and further studies about the differences in body fat distribution among female students and subsequent effects on measurements are recommended.

\section{Acknowledgement}

We appreciate (2012-2013) Year 2 Medical Students and Medical Lab Year 2 Practical for their support in 
this study. Furthermore, I fully acknowledge support of Professor Dr D. Kamarudin D. Mudin - School of Medicine, University Malaysia Sabah in his fullest support to my writing.

\section{References}

1. Food and Agricultural Organization. Incorporating nutrition consideration into development policy and programme. Rome: FAO, 2004.

2. World Health Organization. Ten facts on nutrition. October 2012. http://www.who.int/ features/factfiles/nutrition/en/ (accessed June 2014)

3. Food and Agricultural Organization. ICN2 Second International Conference on Nutrition. Better nutrition Better life. Rome, Italy, 19-21 November, 2014.

4. World Health Organization. Obesity and overweight, Fact sheet No.311. http://www.who.int/ mediacentre/factsheets/fs311/en/ (accessed June 2014)

5. Center for Disease Control and Prevention (CDC). National Health and Nutrition Examination Survey. Anthropometric Procedures Manual. Hyattsville: CDC, 2007.

6. Masaharu K, Deborah Ke, Hayato U, Colin WB. Differences in the relationship between BMI and percentage body fat between Japanese and Australian-Caucasian young men. $\mathrm{Br} J \mathrm{Nutr}$ 2006; 95:1002-7

7. Saima S, Abdul MC, Muhammad NK. Anthropometric correlates of blood pressure in hypertensive subjects in Lahore, Pakistan. SouthEast Asia J of Public Health 2012;2:22-7.

8. World Health Organization Expert Consultation. Appropriate body-mass index for Asian populations and its implications for policy and intervention strategies. Lancet 2004; 363: 15763.

9. James WP, Chunming C, Inoue S. Appropriate Asian body mass indices. Obes Rev 2002; 3 : 139.

10. Ministry of Health, Malaysia. Clinical Practice Guidelines on Management of Obesity 2004. Kulalumpur: Ministry of Health, Malaysia, 2004.

11. Lim TO, Ding LM, Zaki M, Suleiman AB, Fatimah S, Siti S, et al. Distribution of body weight, height and body mass index in a national sample of Malaysian adults. Med J Malaysia 2000; 55: 108-28.

12. Wolf AM, Colditz GA. Current estimates of the economic cost of obesity in the United States. Obes Res 1998; 6: 97-106.
13. Harrison GG, Buskirk ER, Lindsay Carter JE. Skinfold thickness and measurement technique. In: Lohman TG, Roche AF, Martorell R. Anthropometric Standardization Reference Manual. Champaign IL: Human Kinetics Press, 1988.

14. TANITA Body Fat Analyzer. http:// www.tanita.com/en/body-composition-analyzer/ (accessed June 2014)

15. SECA height and Weight Measure. http:// www.seca.com/en us/products/all-products/ product-details/seca284.html (accessed at June 2014)

16. Body Fat Caliper. htt p:// www.accumeasurefitness.com/ (accessed at June 2014)

17. Fahey TD, Insel PM, Roth WT. Lab A6-3 Alternative Skinfold Measurement Formula, Fit and Well, 6th edition, 2005, The McGraw-Hill Companies. http://www.umich.edu/ exphysio/ m v s. $240 / \mathrm{Ad} \mathrm{d} \mathrm{i} \mathrm{t} \mathrm{o} \mathrm{n} \mathrm{a} \mathrm{l} \mathrm{L} \mathrm{a} \mathrm{b} \mathrm{s} \mathrm{/}$ Pred.Bodyfat.Skinfold.6.3.pdf (assessed June 2014)

18. World Health Organization. Obesity: Preventing and Managing the Global Epidemic. Report of a WHO Consultation. WHO Technical Report Series 894. Geneva: WHO, 2000.

19. Snijder MB, van Dam RM, Visser M, Seidell JC. What aspects of body fat are particularly hazardous and how do we measure them? Int $J$ Epidemiol 2006; 35:83-92.

20. Frankenfield DC, Rowe WA, Cooney RN, Smith JS, Becker D. Limits of body mass index to detect obesity and predict body composition. Nutrition 2001;17:26-30.

21. Peltz G, Aguirre MT, Sanderson M, Fadden MK. The role of fat mass index in determining obesity. Am J Hum Biol 2010; 22:639-47.

22. Zhang X, Shu XO, Yang G, Li H, Cai H, Gao YT, Zheng W. Abdominal adiposity and mortality in Chinese women. Arch Intern Med 2007; 167:886-92.

23. Calling S, Hedblad B, Engström G, Berglund G, Janzon L. Effects of body fatness and physical activity on cardiovascular risk: Risk prediction using the bioelectrical impedance method. Scand J Public Health 2006;34:568-75.

24. Chumlea WC, Guo SS. Assessment and prevalence of obesity: Application of new methods to a major problem. Endocrine 2000;13:13542 .

25. Heimmel J, Patel S, Cody R, Bachmann G. Evaluation of physical fitness in an ambulatory setting. Am J Obstet Gynecol 2007;196: 522.e14.

26. Nooyens AC, Koppes LL, Visscher TL, Twisk 
JW, Kemper HC, Schuit AJ, et al. Adolescent skinfold thickness is a better predictor of high body fatness in adults than is body mass index: The Amsterdam Growth and Health Longitudinal Study. Am J Clin Nutr 2007;85:1533-9.

27. Pietrobelli A, Rubiano F, St-Onge MP, Heymsfield SB. New bioimpedance analysis system: Improved phenotyping with whole-body analysis. Eur J Clin Nutr 2004;58:1479-84.

28. Sun SS, Chumlea WC, Heymsfield SB, Lukaski HC, Schoeller D, Kuczmarski RJ, et al. Development of bioelectrical impedance analysis prediction equations for body composition with the use of a multi-component model for use in epidemiologic surveys. Am $J$ Clin Nutr 2003;77:331-40.

29. Segal K, Van Loan M, Fitzgerald P, Hodgdon J, Van Itallie T. Lean body mass estimation by bioelectrical impedance analysis: A four-site cross-validation study. Am J Clin Nutr 1988;47:7 -14 .

30. Schreiner PJ, Terry JG, Evans GW, Hinson WH, Grouse II Jr, Heiss G. Sex specific associations of magnetic resonance imaging-derived intra-abdominal and subcutaneous fat areas with conventional anthropometric indices. Am J Epidemiol 1996;144:335-45.

31. WHO Multicentre Growth Reference Study Group. Reliability of anthropometric measurements in the WHO Multicentre Growth Reference Study. Acta Pcediatrica 2006; Suppl 450:38-46.

32. Lohman TG, Roche AF, Martorell R (eds). Anthropometric Standardization Reference Manual. Champaign IL: Human Kinetics Books; 1988.

33. Martorell R, Habicht JP, Yarbrough C, Guzman $\mathrm{G}$, Klein RE. The identification and evaluation of measurement variability in the anthropometry of preschool children. Am $J$ Phys Anthropol 1975;43:47-52.

34. Foster TA, Berenson GS. Measurement error and reliability in four pediatric cross-sectional surveys of cardiovascular disease risk factor variables - the Bogalusa Heart Study. J Chronic Dis 1987;40:13-21.

35. Chumlea WC, Guo S, Kuczmarski RJ, Johnson CL, Leahy CK. Reliability of anthropometric measurements in the Hispanic Health and Nutrition Examination Survey (HHANES 1982_/1984). Am J Clin Nutr 1990;51:902S-7S

36. George D, Mallery P. SPSS for Windows Step by Step: A simple guide and reference. 11.0 update. $4^{\text {th }}$ edition. Boston: Allyn \& Bacon, 2003.

37. Kline P. The handbook of psychological testing. $2^{\text {nd }}$ edition. London: Routledge, 1999. 